\title{
Science funding: championing research in tough times
}

\author{
Substantial cuts in fiscal spending, triggered by the global economic crisis, highlight a pressing need to safe- \\ guard funding to ensure the future health of the scientific research enterprise.
}

The financial crisis of the past few years has led to deep cuts in funding for scientific research by governments and charitable organizations, hiring freezes across university departments and academic institutes, and downsizing and restructuring in the life sciences industry. Despite signs of some reprieve, the global economy remains fragile, and the future of science funding continues to be at risk.

In 2002, the European Union (EU) set a target to devote $3 \%$ of its gross domestic product (GDP) to research and development (R\&D) by 2010 . In recent years, however, it progressed only marginally towards that goal. For example, in 2008, R\&D expenditure in the EU averaged only $1.92 \%$ of the GDP, significantly lower than in the USA (2.79\% GDP) and Japan (3.45\% GDP) for the same year, according to Eurostat data, and nominal R\&D spending in the EU decreased by $1.3 \%$ between 2008 and 2009, according to the European Commission's 2011 Innovation Union Competitiveness report. Having failed to reach the $3 \%$ GDP spending target for R\&D in 2010, the EU reset the same objective for 2020. However, the current recessionary climate threatens to stifle scientific funding once more. Instead of increased investment, recent years have seen science spending frozen in the UK, with government $R \& D$ expenditure failing to match that of other developed countries. Circumstances have been progressively worsening in the eurozone, where several countries are in dire financial straits. Spain, which had in previous years significantly boosted investment in research, has now proposed a 25\% cut in R\&D expenditure for 2012 .

The financial downturn has also had a detrimental impact on non-governmental funding. Cancer Research UK, one of the largest charities in the UK, recently announced a $10 \%$ cut in basic research funding over the next three years, owing in part to reduced endowments. Science funding by the Wellcome Trust, another key player in biomedical research in the UK, was also reduced from 461.7 million GBP in 2009 to 377.8 million in 2011. More recently, the Global Fund to Fight AIDS, Tuberculosis and Malaria halted funding for its treatment and prevention projects until 2014.

With several countries contending with tough austerity measures, and with the fear of a deeper global recession persisting, governments face difficult choices of monetary allocation with reduced budgets. In these challenging times, it is important for policy-makers to recognize the necessity of investing in scientific research. Biomedical breakthroughs, technological innovation and tackling pressing environmental issues all require sustained scientific development, from basic discovery to final application. Equally important is the role of science in economic recovery, spurring new ventures based on scientific discoveries and creating new jobs. Potential repercussions of slashed research budgets can have long-term consequences that would be difficult to readily reverse. For example, reduced job opportunities, due to hiring freezes and downsizing in academia and the industry, could result in scientists emigrating to more welcoming employment climates, with the danger of a 'brain-drain' looming even for traditional strongholds of research, such as the USA and UK. Decreased research resources could limit scientific vision and opportunities for collaborative research, a crucial facet of modern multidisciplinary research. Funding pressures also encourage a tendency to redirect priorities towards more readily applicable projects to achieve more immediate returns. Funding by the UK research councils already requires statements on the potential impact of the proposed research on the economy and society. Stating limited resources as a contributing factor, the Engineering and Physical Sciences Research Council (EPSRC) has now included 'National Importance' over a 10-50 year period as a funding criterion in its 'Shaping Capability' strategy, asking applicants to project the potential impact of their work over that time span. Policies that favour practical applicability over basic discovery threaten to reduce funding available for basic research, and it is important to resist this trend. Even though the outcome and impact of basic science can never be fully predicted, it may have unexpected, lasting effects in the future. Failed projects, false starts and serendipity are integral to the research process, and thus the inquisitive spirit of scientists should be nurtured by supporting both basic and applied research.

Recent initiatives for increased science funding have indicated that some policy-makers do recognize the importance of continued support for research. The Horizon 2020 proposal of the European Commission, which, if ratified in 2013, will inject 80 billion EUR into European research between 2014 and 2020, and the announcement of a further 100 million GBP for science and engineering in the 2012 UK budget, are steps in the right direction. Nevertheless, sustaining scientific progress will need even further investment.

In times of economic crisis, it is important to remember the old adage: research is a long-distance race, not a sprint. Investing in research is investing in the future, and requires a long-term commitment to the accumulation of knowledge, the testing of basic principles, and the translation of these discoveries into practical applications that impact everyday life. Safeguarding the future of scientific development will require bold decisions and long-term vision by policy-makers. 